\title{
Correction to: Tsunamis from prospected mass failure on the Marsili submarine volcano flanks and hints for tsunami hazard evaluation
}

\author{
G. Gallotti ${ }^{1}$ (I) $\cdot$ F. Zaniboni ${ }^{1} \cdot$ G. Pagnoni ${ }^{1} \cdot$ C. Romagnoli ${ }^{2} \cdot$ F. Gamberi ${ }^{3} \cdot$ M. Marani $^{3} \cdot$ S. Tinti $^{1}$ \\ Published online: 5 March 2021 \\ (C) International Association of Volcanology \& Chemistry of the Earth's Interior 2021
}

Correction to: Bulletin of Volcanology (2021) 83: 2 https://doi.org/10.1007/s00445-020-01425-0

The original version of this article unfortunately contained a mistake. The following figures appeared in the wrong order in the original paper, and are given here in the correct order.

The following figures appeared in the wrong order in the original paper, and are given here in the correct order.

The online version of the original article can be found at https://doi.org/ 10.1007/s00445-020-01425-0

G. Gallotti

glauco.gallotti2@unibo.it

1 Department of Physics and Astronomy (DIFA), University of Bologna, Bologna, Italy

2 Department of Biological, Geological, and Environmental Sciences (BIGEA), University of Bologna, Bologna, Italy

3 Institute of Marine Sciences, National Research Council (ISMAR-CNR), Bologna, Italy 


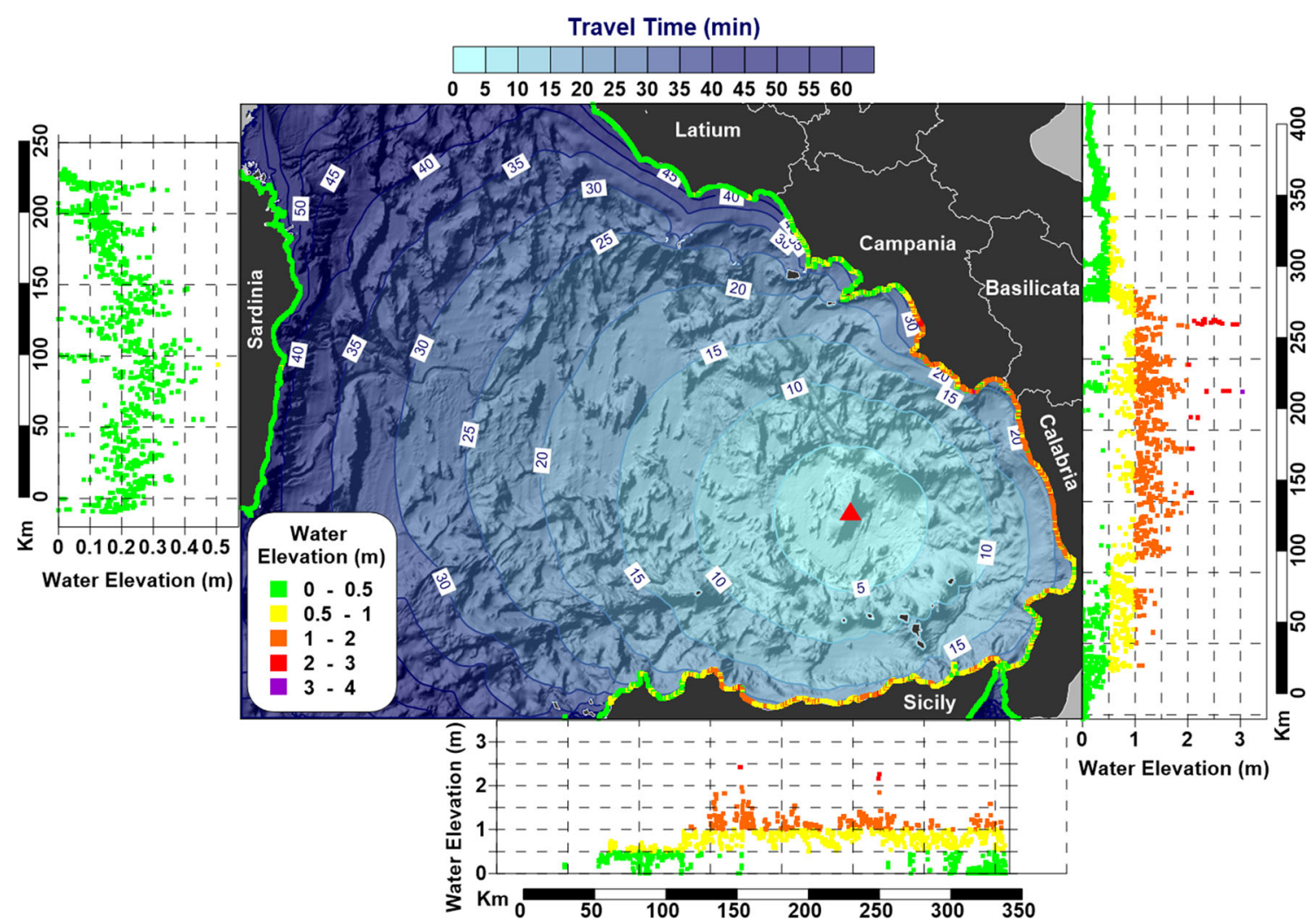

Fig. 12 Maximum water elevation along the coasts of the Tyrrhenian Sea, computed for the landslide case (d). See caption of Fig. 9 for details

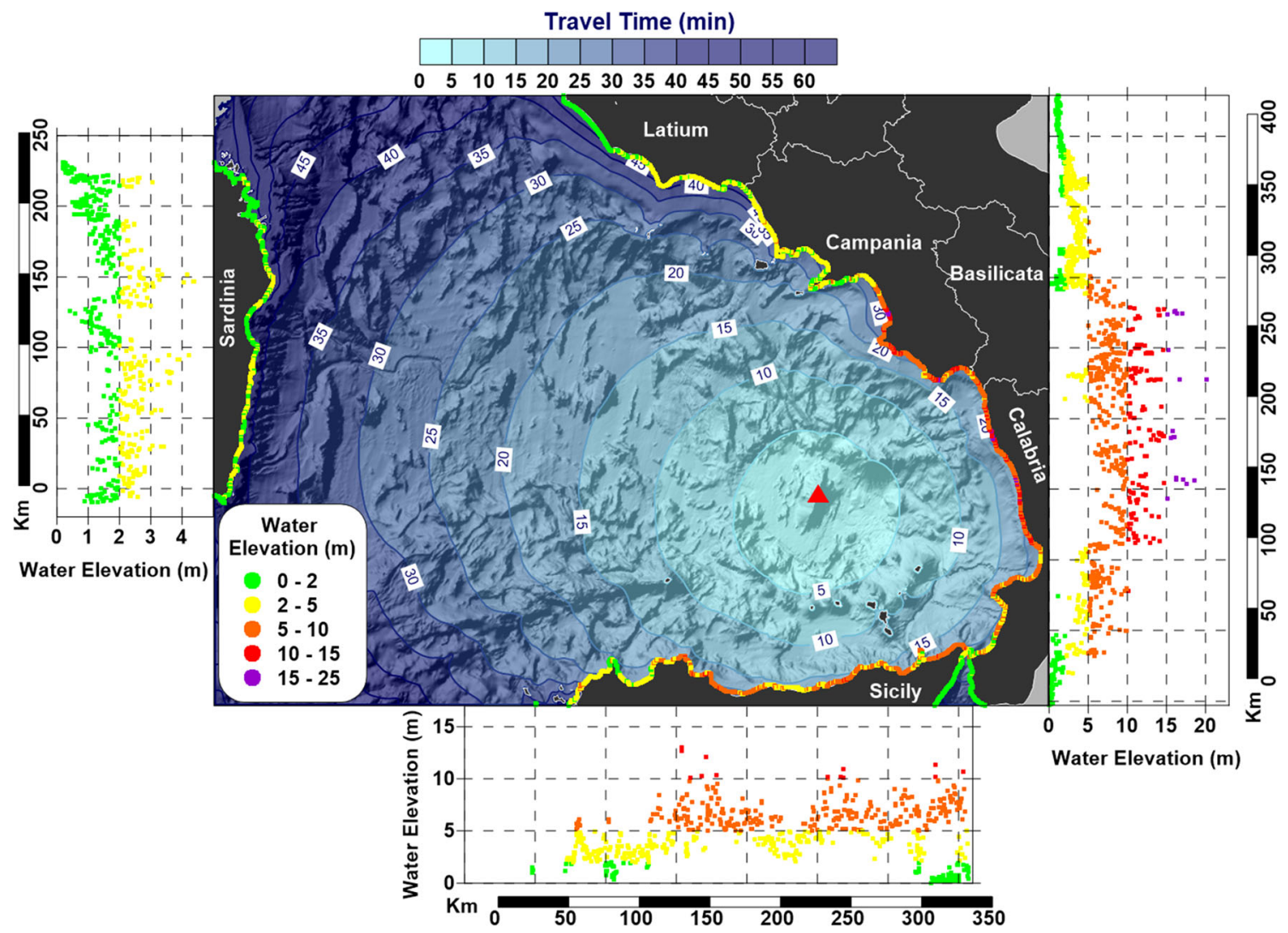

Fig. 13 Maximum water elevation along the coasts of the Tyrrhenian Sea, computed for the landslide case (e). See caption of Fig. 9 for details 